\title{
Rare Presentation of Acute Lymphoblastic Leukemia - A Case Report
}

\author{
Nafe Navid Chinde ${ }^{1}$, Simran Kaur ${ }^{2}$, Sushma Laxma Reddygari ${ }^{3}$ \\ 1, 2, 3 Department of General Medicine, Maharishi Markandeshwar Institute of \\ Medical Sciences and Research, Mullana University Road, Mullana, Haryana, India.
}

\section{INTRODUCTION}

Acute lymphoblastic leukaemia / lymphoblastic lymphoma is the most common childhood malignancy. Leukaemia and lymphoma are clinical presentations of the same disease. It is estimated that approximately 2500 to 3500 new cases are diagnosed each year in the United States, with an incidence of approximately 3.4 cases per 100,000. Number of the cases vary all over the world which is due to diagnostic and reporting differences. ${ }^{1,2}$ Leukaemia, especially acute types, can lead to intracranial haemorrhage (ICH) with high morbidity and mortality. It was reported that ICH occurred in $2.8 \%$ adult patients with haematological malignancies. ${ }^{3,4}$ But majority of cases presented with intraparenchymal haemorrhage, only rare cases have been seen to present with sub dural haemorrhage.

\section{PRESENTATION OF CASE}

An 18-year-old male was brought to the emergency department with complaints of headache for 15 days and fever and multiple episodes of vomiting for 2 days. At the time of presentation, patient was conscious and oriented with Glasgow Coma Scale (GCS) 15 / 15. At presentation, pulse rate (PR) was 56 / min, blood pressure (BP) was $110 / 70 \mathrm{mmHg}$ and respiratory rate (RR) was $24 \mathrm{~min}$. He was afebrile and oxygen saturation (Spo2) was $99 \%$ on room air. General and systemic examination was normal, no papilloedema was seen, no bleeding manifestations were reported or observed, no signs of meningeal irritation were seen and no history of trauma was reported.

Patient's non-contrast computed tomography (NCCT) head was suggestive of thin left fronto-parietal isodense collection, subacute subdural haematoma (SDH) with midline shift to the right.

Patients laboratory reports were obtained. Haemoglobin ( $\mathrm{Hb})$ was $8.1 \mathrm{gm} \%$, total leukocyte count (TLC) was 11000, differential leukocyte count (DLC)-polymorphs: 1, lymphocytes: 50, atypical blastoid cells: 49 and platelet count: 77000. Other routine lab tests were within normal limits and ultrasound sonography (USG) abdomen was normal. Patient was investigated for probability of other differentials, and he was found to be Covid-19 negative, no malarial parasites were seen, dengue serology by enzyme-linked immunosorbent assay (ELISA) test was also negative, test for scrub typhus was also negative.

Magnetic resonance imaging (MRI) brain was suggestive of extra axial collection measuring $11 \mathrm{~mm}$ at maximum width appearing isointense on T1 weighted image and hyperintense on T2 weighted / flair images were seen along left cerebral convexity in fronto-temporo-parieto occipital region suggestive of sub-acute to chronic subdural hematoma underlying sulcal spaces and left sylvian fissures were partially wiped out. There was a mass effect on left lateral ventricle with mid-line shift $11 \mathrm{~mm}$ towards right with sub falcine and mild descending trans tentorial herniations. (Figure 1).

\author{
Corresponding Author: \\ Dr. Chinde Nafe Navid, \\ Department of General Medicine, \\ Maharishi Markandeshwar Institute of \\ Medical Sciences and Research, \\ Mullana University Road, \\ Mullana, Haryana, India. \\ E-mail:nafechinde@gmail.com
}

DOI: $10.14260 / j e m d s / 2021 / 179$

How to Cite This Article:

Chinde NN, Kaur S, Reddygari SL. Rare presentation of acute lymphoblastic leukemia - a case report. J Evolution Med Dent Sci 2021;10(11):839-840, DOI: 10.14260/jemds/2021/179

Submission 14-10-2020,

Peer Review 21-01-2021,

Acceptance 27-01-2021,

Published 15-03-2021.

Copyright (c) 2021 Nafe Navid Chinde et al. This is an open access article distributed under Creative Commons Attribution License [Attribution 4.0 International (CC BY 4.0)] 
Patient was advised bone marrow biopsy in consideration for acute leukaemia which was suggestive of hypercellular marrow with sheets of immature cells (Figure 2 ) replacing the normal haematopoietic elements giving an impression of acute lymphoblastic leukaemia.

\section{DISCUSSION OF MANAGEMENT}

During the course of treatment, initially patient was kept in intensive care unit for observation and oncology opinion was taken, and they advised induction therapy for acute lymphoblastic leukaemia. Once the patient was stabilised, neurosurgery consultation was taken and patient was advised conservative management and then shifted to the ward after he improved symptomatically. During last the follow-up, patient was on induction therapy with vincristine, dexamethasone and asparaginase.
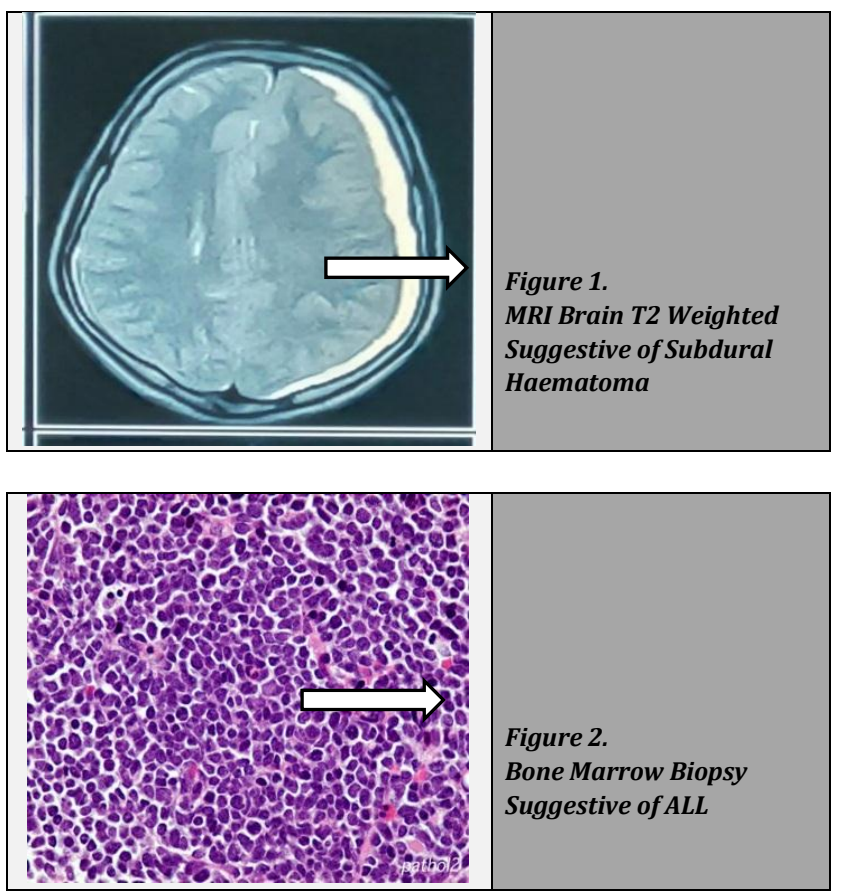

\section{DISCUSSION}

This patient presented with headache, fever and vomiting and was found to have subdural haematoma on NCCT head and subsequently confirmed on MRI brain. His haematological investigations were suggestive of acute leukaemia which was confirmed with bone marrow biopsy. In the study by Chen CY, the incidence of subdural haematoma was just $0.47 \%$ in patients with haematological malignancies. Acute SDH generally has history of head trauma. ${ }^{5,6}$ Chronic SDH usually occurs after 3 weeks so there is a probability that the history of head trauma may be forgotten. But in patients with haematological malignancies, head trauma may not be necessary which can be seen in this case. The possible risk factors for causing intracerebral haemorrhage in a patient with acute leukaemia may include thrombocytopenia, platelet dysfunction, disseminated intravascular coagulation (DIC), coagulation factor deficiency, hyperleukocytosis, vessel wall abnormalities, hypertension and sepsis. Our patient had thrombocytopenia all the time. Subdural haemorrhage caused by haematological malignancies such as acute leukaemia may be associated with a higher possibility of neurosurgery and the risk of potential adverse outcomes. Currently there is no known way to prevent intracerebral haemorrhage including subdural haemorrhage in patients with acute leukaemia, but prophylactic platelet transfusions may help. ${ }^{7}$ Considering high probability of subdural haematoma in these patients we should ask patients to avoid head trauma.

\section{CONCLUSIONS}

Subdural haematoma in a patient with acute lymphoblastic leukemia is extremely rare. Acute subdural haematoma can occur in acute lymphoblastic leukemia patients without definite head trauma. Haematological malignancies should be considered when a patient, who has had no history of head trauma but on investigations found to have subdural haematoma and low-grade fever, headache and vomiting; with the exacerbation of disease and worse laboratory data which may suggest higher risk of occurrence of subdural haematoma. In addition to active diagnosis and treatment, acute leukaemia patients should be protected from even mild head trauma to avoid subdural haematoma due to increased tendency of bleeding.

Financial or other competing interests: None.

Disclosure forms provided by the authors are available with the full text of this article at jemds.com.

\section{REFERENCES}

[1] Steliarova-Foucher E, Colombet M, Ries LAG, et al. International incidence of childhood cancer, 2001-10: a population-based registry study. The Lancet Oncology 2017;18(6):719-31.

[2] Ward E, De Santis C, Robbins A, et al. Childhood and adolescent cancer statistics, 2014. CA Cancer J Clin 2014;64(2):83-103.

[3] Kim H, Lee JH, Choi SJ, et al. Risk score model for fatal intracranial hemorrhage in acute leukemia. Leukemia 2006;20(5):770-6.

[4] Dayyani F, Mougalian SS, Naqvi K, et al. Prediction model for mortality after intracranial hemorrhage in patients with leukemia. Am J Hematol 2011;86(7):546-9.

[5] Chen CY, Tai CH, Tsay W, et al. Prediction of fatal intracranial hemorrhage in patients with acute myeloid leukemia. Ann Oncol 2009;20(6):1100-4.

[6] Chen $\mathrm{CY}$, Tai $\mathrm{CH}$, Cheng A, et al. Intracranial hemorrhage in adult patients with hematological malignancies. BMC Med 2012;10:97.

[7] Blajchman MA, Slichter SJ, Heddle NM, et al. New strategies for the optimal use of platelet transfusions. Hematol Am Soc Hematol Educ Program 2008: p. 198204. 